\title{
Preparation and Structural Characterization of New Photopolymerizable Transparent Aluminum-Phosphate Hybrid Materials as Resins for 3D Printing
}

Gabriel T. Tayama ${ }^{1}$, Silvia Helena Santagneli ${ }^{*}$, Hellmut Eckert ${ }^{2}$, Shane Pawsey ${ }^{3}$, Younes Messaddeq ${ }^{1,4^{*}}$

\author{
1 - Chemistry Institute, São Paulo State University - UNESP, Araraquara, SP, Brazil \\ 2- São Carlos Institute of Physics, University of São Carlos -USP, São Carlos, SP, Brazil \\ 3- Bruker BioSpin Corporation, 15 Fortune Drive, Billerica, MA, USA \\ 4-Centre de Optique, Photonique et Laser-COPL - Universite Laval
}

\section{Supporting information}


Table S1: Mass of reactants weighted for a $10 \mathrm{~g}$ batch of each composition. $0.1 \mathrm{~g}$ of TPO was added afterwards.

\begin{tabular}{|c|c|c|c|}
\hline $\begin{array}{c}\text { Al/(Al+P) molar } \\
\text { ratio (\%) }\end{array}$ & $\begin{array}{c}\text { HEMA } \\
(\mathbf{g})\end{array}$ & $\begin{array}{c}\text { HEMA-P } \\
(\mathbf{g})\end{array}$ & $\begin{array}{c}\text { Al(MAEAA)2 } \\
(\mathbf{g})\end{array}$ \\
\hline 0 & 5 & 5 & 0 \\
\hline 10 & 5 & 3.583 & 1.417 \\
\hline 25 & 5 & 2.287 & 2.713 \\
\hline 40 & 5 & 1.482 & 3.514 \\
\hline 50 & 5 & 1.097 & 3.903 \\
\hline
\end{tabular}

Table S2: Concentration of reactants and Ethyl Methacrylate (EtM) groups for $10 \mathrm{~g}$ of each composition.

\begin{tabular}{|c|c|c|c|c|}
\hline $\begin{array}{c}\text { Al/(Al+P) } \\
\text { molar ratio (\%) }\end{array}$ & $\begin{array}{c}\text { HEMA } \\
(\mathrm{mol})\end{array}$ & $\begin{array}{c}\text { HEMA-P } \\
(\mathrm{mol})\end{array}$ & $\begin{array}{c}\text { Al(MAEAA)2 } \\
(\mathrm{mol})\end{array}$ & $\begin{array}{c}\text { EtM } \\
\text { groups } \\
(\mathrm{mol})\end{array}$ \\
\hline 0 & 0.049 & 0.026 & 0 & 0.070 \\
\hline 10 & 0.049 & 0.019 & 0.002 & 0.068 \\
\hline
\end{tabular}




\begin{tabular}{|c|c|c|c|c|}
\hline 25 & 0.049 & 0.012 & 0.004 & 0.066 \\
\hline 40 & 0.049 & 0.008 & 0.005 & 0.065 \\
\hline 50 & 0.049 & 0.006 & 0.006 & 0.065 \\
\hline
\end{tabular}

Number of EtM groups is calculated from reactants using the following stoichiometry:

$1 / 1$ (EtM/HEMA), 0.8/1(EtM/HEMA-P) and 2/1(EtM/Al(MAEAA) $)_{2}$. EtM Molar

Concentration in the samples is calculated using the equation:

$$
\operatorname{EtM}(\% \mathrm{~mol})=\frac{\text { Total EtM }}{\text { Total EtM }+n_{\text {HEMA }-P}+n_{\operatorname{Al}(M A E A A) 2}}
$$



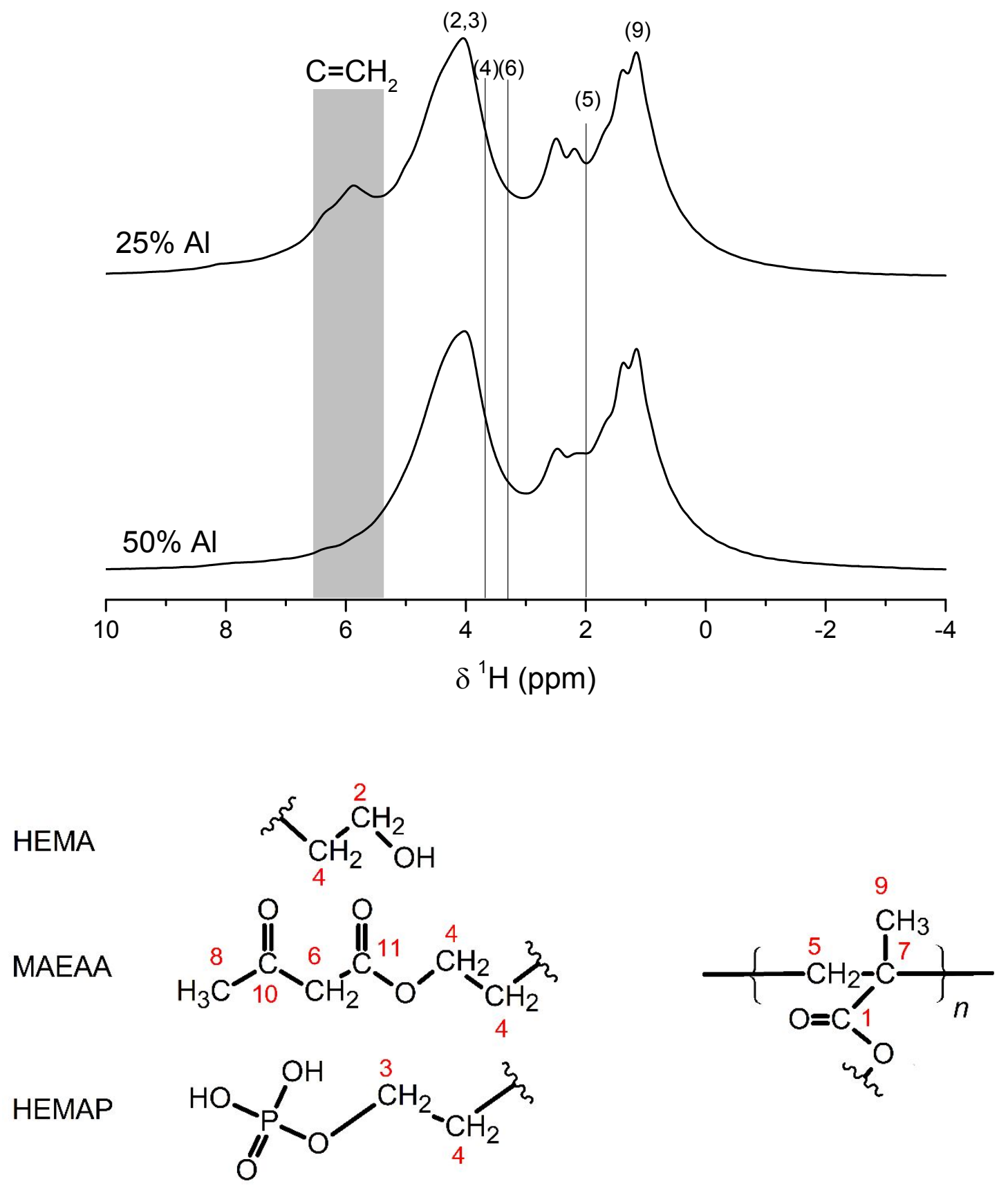

Figure S1. ${ }^{1} \mathrm{H}$ MAS NMR spectra and structural assignment for samples containing 25 and $50 \% \mathrm{Al} /(\mathrm{P}+\mathrm{Al})$ at $60 \mathrm{kHz}$. 
The ${ }^{1} \mathrm{H}$ MAS spectrum, on Figure, shows broad proton signals associated to unsaturated carbons. Signal identification was assisted by ${ }^{13} \mathrm{C}-{ }^{1} \mathrm{H}$ CP-HETCOR spectra measured(moles $\mathrm{Al}) \times$ he on $25 \% \mathrm{Al} /(\mathrm{Al}+\mathrm{P})$ sample, shown in Figure $\mathrm{S} 2$, with:150 $\mu \mathrm{s}$ and $500 \mu$ s contact times. Similar results were obtained for samples with $x=A l /(A l+P)=$ $50 \%$, therefore they are not presented here. Based on the cross-peaks, we can attribute the following proton signals: (I) 1 ppm: methyl groups from polymerized methacrylate substructure (H9); (II) 2 ppm: $\mathrm{CH}_{2}$ within the polymeric chain (H5); (III) 3.7 and 4.0 ppm: $\mathrm{CH}_{2}$ from ethyl ester group (H2, H3) and (H4), respectively; (IV) $3.3 \mathrm{ppm}$ : (H6) from MAEAA. With small contact time $(150 \mu \mathrm{s})$, the observed cross-peaks are associated with polarization transfer involving directly bonded $\mathrm{H}$ atoms only, and (I), (II) and (III) ${ }^{1} \mathrm{H}-$ ${ }^{13} \mathrm{C}$ correlation are observable, although in cases (III) and (II) the ${ }^{1} \mathrm{H}-{ }^{13} \mathrm{C}$ dipolar interactions are weakened owing to $\mathrm{CH}_{3}$ and $\mathrm{CH}_{2}$ rotational motion. With longer contact time $(500 \mu \mathrm{s})$, polarization transfer through space results in higher signal to noise ratios and in longer-range correlations. Appreciable changes occur for $500 \mu s$ contact time, with stronger ${ }^{1} \mathrm{H}-{ }^{13} \mathrm{C}$ correlation from (I) and (II) cross-peaks and observation of 
correlations involving IV. Quaternary carbon (45 ppm) cross-peak with $1.6 \mathrm{ppm}$ proton signal results from cross-polarization with both methyl groups (1 ppm) (C7-H9) and polymeric chain $\mathrm{CH}_{2}(2 \mathrm{ppm})(\mathrm{C} 7-\mathrm{H} 5)$. In the ${ }^{1} \mathrm{H}$ MAS spectrum, $\mathrm{C}=\mathrm{CH}_{2}$ signals at $6 \mathrm{ppm}$ are also observed from unpolymerized methacrylate.

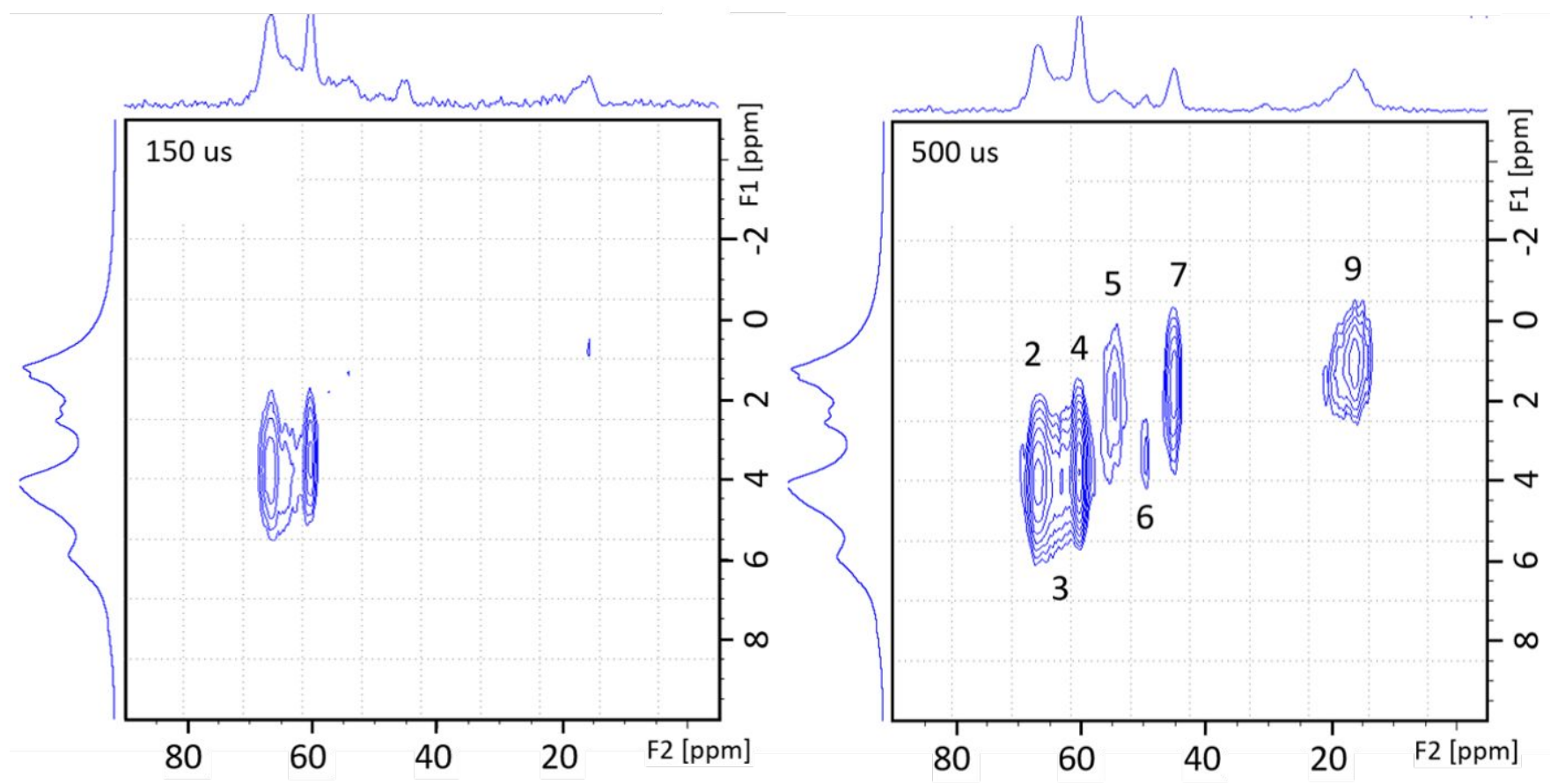

Figure S2. ${ }^{13} \mathrm{C}\left\{{ }^{1} \mathrm{H}\right\}$ HETCOR spectra for a sample with $\mathrm{x}=\mathrm{Al} /(\mathrm{Al}+\mathrm{P})=25 \%$ with $150 \mu \mathrm{s}$ and $500 \mu$ s contact time. 

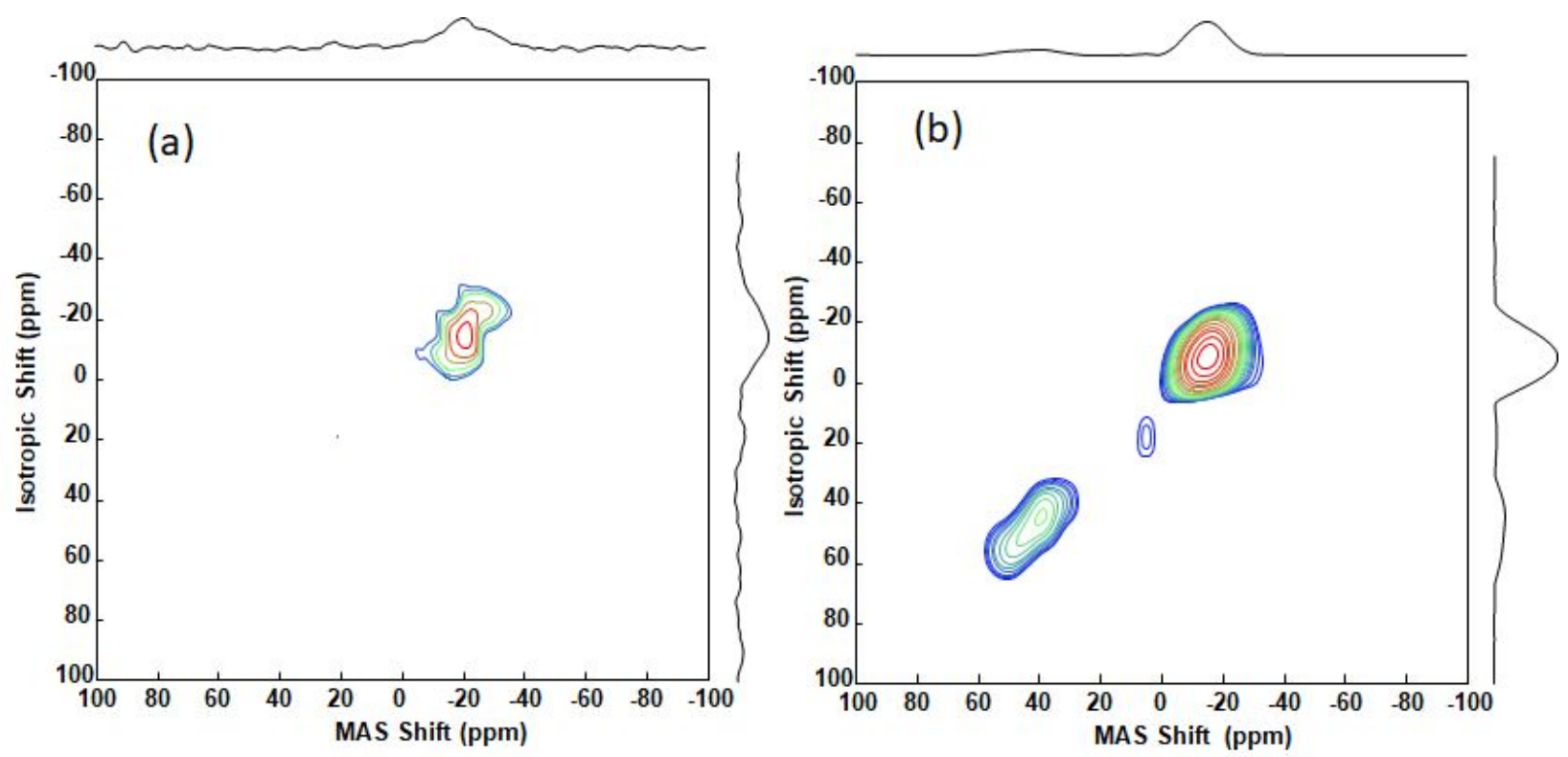

Figure S3. ${ }^{27} \mathrm{Al}$ TQMAS NMR spectra of the samples with $\mathrm{x}=\mathrm{Al} /(\mathrm{Al}+\mathrm{P})=10 \%$ (a) and $40 \%$ (b). 